Number of pages: 23

Number of figures: 7

Number of Tables: 2

\title{
The transmission of vibration through gloves: effects of push force, vibration magnitude and inter-subject variability
}

\author{
Helga E. Laszlo1, Michael J. Griffin² \\ ${ }^{1}$ Technical Department of Faculty of Horticultural Science, Corvinus University of Budapest \\ Villányi út 29-43, Budapest, H-1118, Hungary \\ Tel.:+36 1 4826196, E-mail: laszlohelgaelvira@gmail.com
}

${ }^{2}$ Human Factors Research Unit, Institute of Sound and Vibration Research, University of Southampton

Highfield, Southampton, SO17 1BJ, United Kingdom

Tel.:+44 (0)2380 592277 , E-mail: mjg@isvr.soton.ac.uk

Keywords: hand-arm vibration, anti-vibration glove, vibration magnitude, handle push force 


\begin{abstract}
The extent to which a glove modifies the risks from hand-transmitted vibration is quantified in ISO $10819: 1996$ by a measure of glove transmissibility determined with one vibration magnitude, one contact force with a handle, and only three subjects. This study was designed to investigate systematically the vibration transmissibility of four 'anti-vibration' gloves over the frequency range 16 to $1600 \mathrm{~Hz}$ with 12 subjects, at six magnitudes of vibration ( 0.25 to $8.0 \mathrm{~ms}^{-2}$ r.m.s.) and with six push forces ( $5 \mathrm{~N}$ to $80 \mathrm{~N}$ ). The four gloves showed different transmissibility characteristics that were not greatly affected by vibration magnitude but highly dependent on push force. In all conditions, the variability in transmissibility between subjects was as great as the variability between gloves. It is concluded that a standardised test of glove dynamic performance should include a wide range of hands and a range of forces representative of those occurring in work with vibratory tools.
\end{abstract}

\title{
Relevance of the findings for ergonomics practice
}

The transmission of vibration through anti-vibration gloves is highly dependent on the push force between the hand and a handle and also highly dependent on the hand that is inside the glove. The influence of neither factor is well reflected in ISO 10819:1996, the current standard for anti-vibration gloves.

\section{Running head}

Anti-vibration gloves 


\section{Introduction}

Prolonged regular use of powered hand-held tools can induce disorders of the vascular and sensorineural systems of the hand, collectively known as the hand-arm vibration syndrome. The measurement and the evaluation of hand-transmitted vibration on powered hand tools, and the assessment of risks associated with hand-transmitted vibration, are mostly based on guidelines and dose-response relationships provided in ISO 5349-1 (2001).

Several methods may be considered for minimising the risks of vibration-induced injuries, including the use of personal protective equipment in the form of 'anti-vibration gloves'. The requirements for a glove to be called an anti-vibration glove are specified in International Standard 10819 (1996) and a method of measuring the vibration transmissibility of resilient materials loaded by the hand-arm system is proposed in International Standard 13753 (1998). The method in ISO 13753 (1998) assumes a glove does not change the biodynamic properties of the hand-arm system and that the dynamic response of the glove-hand-arm system is linear.

The glove-hand-arm system can be modelled with the hand and the glove as independent, but coupled, mechanical systems so as to predict glove transmissibility (e.g. Dong et al. $2005,2009)$. Since the dynamics of the hand-arm system without a glove can be strongly influenced by coupling forces at the hand (e.g. Pyykkö et al. 1976, Griffin et al. 1982, Aatola 1989, Gurram et al. 1994, 1995) and, to a lesser extent, the vibration magnitude (e.g. Reynolds and Keith 1977, Gurram et al. 1994, 1995, Besa et al. 2007), it can be expected that glove transmissibility will also be influenced by these factors (Griffin 1990, Dong et al. 2004).

The few studies that have investigated the effects of hand forces on glove transmissibility suggest that the force imparted by the operator through a glove can influence glove transmissibility (e.g. Gurram et al. 1994, Hewitt 1998, Smutz et al. 2002). Dong et al. (2002) investigated two anti-vibration gloves used with two pneumatic chipping hammers and with two applied feed forces (50 N and $100 \mathrm{~N}$ ) and concluded that variations in force had most effect on glove transmissibility at high frequencies. Paddan (1997) found that the transmission of vibration through the fingers increased with an increase in pull force from 10 $\mathrm{N}$ to $30 \mathrm{~N}$, but that further increases in force to $50 \mathrm{~N}$ had no effect on finger transmissibility. O'Boyle (2003) found that the transmissibility of material from three anti-vibration gloves increased as the force applied by the palm of the hand increased from 10 to $80 \mathrm{~N}$.

The glove test specified in ISO 10819 (1996) controls both the grip force and the push force, although studies by Hewitt (1998) and Dong et al. (2004) suggest that only the push force has a large effect on the transmission of vibration to the palm of the hand. Paddan (1996) 
reported a marginal effect on weighted glove transmissibility when grip force was varied. The unnecessary control of grip force complicates the method, and controlling grip force to a specified level may not achieve the same pressure when different methods are used for measuring grip force (Griffin 1998).

It has mostly been assumed that the dynamic behaviour of gloves is linear, so that the transmissibility is independent of the vibration magnitude. Hewitt (1998) found that variations in vibration magnitude did not significantly affect the transmissibility, with only about $3 \%$ difference in the transmissibility of a glove excited at 3 and $20 \mathrm{~ms}^{-2}$ r.m.s. O'Boyle (2005) also noted that increasing the vibration magnitude did not have a large effect on the transmissibility of three glove materials, although there were statistically significant increases in transmissibility at some frequencies, especially in the range 160 to $400 \mathrm{~Hz}$.

International Standard 10819 (1996) requires that only three subjects are used when measuring glove transmissibility. Various studies have shown large variability in glove transmissibility associated with the use of different subjects (e.g. Paddan and Griffin 1997, Griffin 1998, Hewitt 1998, Boileau et al. 2002, Paddan 2002, O'Boyle and Griffin 2004a). This makes it possible for a glove to pass or fail the standard test for an anti-vibration glove depending on the choice of test subject.

Further research is required to improve understanding of the factors influencing the transmission of vibration though gloves and increase both the reliability and the applicability of the current anti-vibration glove test. Whereas the ISO 10819:1997 requires one push force and a single vibration magnitude, work with vibratory tools involves a wide range of forces, a wide range of vibration magnitudes, and a wide range of different hands. This study was designed to investigate systematically the effects of push force, vibration magnitude, and inter-subject variability on the vibration transmissibility of gloves. With each push force and each vibration magnitude, the transmissibility of four anti-vibration gloves was determined with 12 subjects so as to determine the extent and the nature of inter-subject variability in glove transmissibility.

\section{Method}

\subsection{Equipment}

The arrangement for measuring glove transmissibility was similar to that recommended in ISO 10819 (1996). A random signal was generated using HVLab software (version 3.81) and low-pass filtered at $1260 \mathrm{~Hz}$ before being fed into a Derritron 1500-watt power amplifier connected to a horizontally orientated Derritron VP85 electrodynamic vibrator. Subjects held an instrumented handle constructed of mild steel with a total mass of $6.0 \mathrm{~kg}$ and a first resonance at $1440 \mathrm{~Hz}$. Strain gauges were mounted on the handle so that the push force on 
the handle could be measured and displayed on an oscilloscope for monitoring and control purposes. A piezoelectric accelerometer (Brüel and Kjær type 4374) was fixed inside the instrumented handle and another accelerometer of the same type was located in a palm adapter as defined in ISO 10819 (1996). Acceleration signals from the handle and the palm adapter were passed through signal conditioning amplifiers and then low-pass filtered at $1260 \mathrm{~Hz}$ before being sampled at 5000 samples per second.

\subsection{Subjects and gloves}

Twelve healthy, right handed, male subjects participated in the study that was approved by the Human Experimentation Safety and Ethics Committee of the Institute of Sound and Vibration Research at the University of Southampton.

The hand size of the participants varied from 8 to 10 , as measured according to EN 420 (1994) using the hand circumference at the metacarpal of the hand. The ages of the subjects varied from 22 to 53 years, their statures ranged from $170 \mathrm{~cm}$ to $186 \mathrm{~cm}$, and their weights ranged from $65 \mathrm{~kg}$ to $90 \mathrm{~kg}$.

Four types full-fingered 'anti-vibration gloves' were investigated: a padded glove (labelled as Glove 1), a silicone filled glove (Glove 2), a gelfoam filled glove (Glove 3), and an air-bladder glove (Glove 4), all size 9.

\subsection{Test conditions and analysis}

Subjects held the handle with their dominant right hand (Figure 1). With an elbow angle of $90^{\circ}\left( \pm 10^{\circ}\right)$ they were asked to apply a push force but no grip force. The applied force was displayed on a scaled oscilloscope to allow subjects to maintain a constant push force throughout the measurements.

\section{FIGURE 1 ABOUT HERE}

The vibration of many hand-held powered tools is predominately in the range 10 to $1000 \mathrm{~Hz}$ (ISO 5349, 2001). For this study, a broad-band random vibration (spectrum $\mathrm{R}$ ) with a flat constant-bandwidth acceleration power spectral density was generated over the frequency range 16 to $1000 \mathrm{~Hz}$. A broad-band spectrum has been found to be a useful alternative to the standardised M and H spectra used in glove testing (Griffin 1998, Dong et al. 2002, 2004, 2005, Paddan 1996). The 30-s duration of vibration suggested in ISO 10819 (1996) has been shown to be inappropriate (Hewitt 1998, Griffin 1998, Paddan 2001), so 10-s periods of excitation were used.

Transfer functions were calculated between the input (i.e. acceleration of the handle) and the output (i.e. acceleration of the palm-glove interface adapter) using the 'cross-spectral density function method'. The transfer function, $H_{\mathrm{io}}(f)$, was determined as the ratio of cross-spectral 
density of the input and output acceleration, $G_{\text {io }}(f)$, to the power spectral density of the input acceleration, $G_{i i}(f)$ :

$$
H_{\mathrm{io}}(f)=G_{\mathrm{io}}(f) / G_{\mathrm{ii}}(f) \text {. }
$$

Frequency analysis was carried out with a resolution $4.88 \mathrm{~Hz}$ and 196 degrees of freedom. From the individual transmissibilities, the transmissibilities at each of the seven preferred octave centre frequencies from $16 \mathrm{~Hz}$ to $1000 \mathrm{~Hz}$ were determined.

Using the frequency-weighting $W_{\mathrm{h}}$ as specified in ISO 5349-1 (2001), an overall transmissibility, TR, was calculated from the ratio of the frequency-weighted acceleration of the palm adaptor to the frequency-weighted acceleration of the handle. This value is not directly comparable to the TR values in ISO 10819 (1996) because it was calculated with a different spectrum and was not corrected by measurements with a bare hand.

Subjects attended the laboratory for two sessions. In the first session, the $\mathrm{R}$ spectrum was generated at six magnitudes of vibration $\left(0.25,0.5,1.0,2.0,4.0\right.$, and $8.0 \mathrm{~ms}^{-2}$ r.m.s., frequency-weighted using $W_{\mathrm{h}}$ according to ISO 5349-1: 2001) with the push force maintained at $50 \mathrm{~N}$. In the second session, subjects applied six different push forces on the handle (5, $10,20,40,50$, and $80 \mathrm{~N}$ ) with the frequency weighted acceleration magnitude constant at 2.0 $\mathrm{ms}^{-2}$ r.m.s. The four gloves, six vibration magnitudes, and six forces were tested in random orders.

In accord with ISO 10819 (1996), the gloves were worn by the subject for at least 3 minutes before commencing vibration measurements. Subjects rested for approximately 2 minutes between the tests. The temperature of the room was controlled at $21^{\circ} \mathrm{C}\left( \pm 2^{\circ} \mathrm{C}\right)$. Prior to testing, the subjects were provided with written instructions on the experiment and the required posture.

\subsection{Statistical analysis}

Non-parametric tests (Friedman test for $k$-related samples, the Wilcoxon matched-pairs signed ranks test for two-related samples, and the Spearman's rank correlation coefficient) were employed in the statistical analysis. Statistical analysis was undertaken using SPSS (version 16.0).

\section{Results}

The means of the overall transmissibilities (i.e. TR values) of each of the four gloves are shown as a function of vibration magnitude in Figure 2 and as a function of push force in Figure 3. Table 1 summarises the mean, minimum, and maximum TR values for each condition and the corresponding coefficients of variation (CoV). The lowest mean TR value 
was obtained with Glove $1(0.513)$ and the highest mean TR value was obtained with Glove 4 (0.927).

FIGURES 2 AND 3 ABOUT HERE

TABLE 1 ABOUT HERE

\subsection{Glove transmissibility as a function of frequency}

When expressed as a function of the frequency of vibration, the four gloves produced different transmissibilities, although with similarities between gloves 3 and 4 (Figure 4). The mean transmissibilities are shown for the frequency range where the mean coherency between the input and output acceleration was greater than 0.9 . The mean transmissibility of Glove 1 exceeded 1.0 (with a peak at $63.5 \mathrm{~Hz}$ ), indicating that it slightly amplified vibration at that frequency, although at high frequencies it provided the greatest attenuation. Around 315 $\mathrm{Hz}$, three of the gloves reduced the vibration magnitude at the hand by $40 \%$ or more (i.e. the transmissibility fell below 0.6 ), and at $500 \mathrm{~Hz}$ all four gloves reduced the vibration magnitude by $70 \%$.

\section{FIGURE 4 ABOUT HERE}

\subsection{Influence of vibration magnitude}

There were only small variations in the $T R$ values as the vibration magnitude varied (Figure 2 and Table 1). Across the six vibration magnitudes and four gloves, the coefficient of variation in the TR values calculated across the 12 subjects varied between 0.049 for Glove 2 at the lowest vibration magnitude and 0.176 for Glove 4 at the highest vibration magnitude (Table 1).

When as expressed as a function of vibration frequency, the glove transmissibilities showed small, but systematic, effects of vibration magnitude (Figure 5). With increasing vibration magnitude, there was evidence of a slight decrease in the resonance frequency (most evident for Glove 1) and a reduction in transmissibility at high frequencies (most evident for Glove 4).

\section{FIGURE 5 ABOUT HERE}

The effect of vibration magnitude on glove transmissibility was statistically significant over most of the frequency range for only Glove 2 and Glove 4 (Table 2). The Spearman rank correlation test showed statistically significant correlations between the magnitude of vibration and the mean $T R$ value for three gloves, but the correlation varied in direction $(r=0.829, p$ (two tailed) $=0.042$ for Glove $1 ; r=-0.943, p$ (two tailed $)=0.005$ for Glove $2 ; r=-1.00$, $p$ (two tailed $)=0.000$ for Glove 4$)$. The TR value therefore increased with increasing vibration 
magnitude for Glove 1, but reduced with increasing vibration magnitude for Glove 2 and Glove 4, with no correlation between TR value and vibration magnitude for Glove 3.

\section{TABLE 2 ABOUT HERE}

\subsection{Influence of push force}

With increasing push force, the TR values increased (Figure 3). Across the six forces, the coefficient of variation in the TR values calculated over the 12 subjects at each push force ranged from 0.088 for Glove 1 at the second highest force to 0.206 for Glove 2 at the lowest force (Table 1).

With all four gloves, with increasing push force the transmissibility increased at all frequencies, with evidence of increases in the resonance frequency as the force increased (Figure 6). There were strong positive correlations between the magnitude of the applied force and the mean TR value $(r=0.943, p$ (two-tailed) $=0.005$ with gloves 2 and 4 , and $r=1.00$, $p($ two-tailed $)=0.000$ with gloves 1 and 3$)$.

\section{FIGURE 6 ABOUT HERE}

At all seven preferred octave centre frequencies from 16 to $1000 \mathrm{~Hz}$, there were statistically significant differences in transmissibility due to force with all four gloves ( $p \leq 0.002$, Friedman).

\subsection{Inter-subject variability}

The coefficients of variation in the overall transmissibilities across the 12 subjects at each vibration magnitude and push force show the extent of inter-subject variability (Table 1). When varying the vibration magnitude, the coefficient of variation varied: the greater the vibration magnitude, the greater the inter-subject variability (the coefficient of variation was in the range 0.049 to 0.097 with $0.25 \mathrm{~ms}^{-2}$ r.m.s. but in the range 0.098 to 0.176 with $8 \mathrm{~ms}^{-2}$ r.m.s.). When varying push force, the coefficient of variation seems to have decreased with increasing force (the coefficient of variation was in the range 0.108 to 0.206 with $5 \mathrm{~N}$ but in the range 0.100 to 0.136 with $80 \mathrm{~N}$ ).

The coefficient of variation in the overall transmissibilities across the four gloves at each vibration magnitude and push force (0.039 to 0.092$)$ tended to be less than the coefficient of variation across the 12 subjects with each condition (0.049 to 0.206$)$ (Table 1$)$.

Large inter-subject variability in transmissibility as a function of the frequency of vibration was apparent for all the gloves (Figure 7).

\section{FIGURE 7 ABOUT HERE}

The correlation between the hand size of the 12 subjects and the mean TR value obtained with each glove was determined for each condition. This showed no systematic pattern for 
positive or negative correlations and only one of the 48 correlations was statistically significant at the 0.05 level (Spearman rank correlation). It may be concluded that the large inter-subject variability in TR values cannot be accounted for by simple measures of hand size as indicated by the hand circumference around the metacarpals.

\section{Discussion}

Although it might seem sensible to use anti-vibration gloves to minimise the risk of vibrationinduced injuries, the vibration attenuation characteristics and any benefits of such gloves are not yet well understood.

The findings of this study indicate that the dynamics of a glove, or the dynamics of the hand, or the dynamics of both the glove and the hand vary when the push force varies. Increasing the force may be expected to increase the stiffness of the glove and increase both the transmissibility and the resonance frequency, as seen in Figure 6. A similar increase in resonance frequency has been observed previously (Książek et al. 2001, Rakheja et al. 2002, Smutz et al. 2002, Dong et al. 2005, 2009). The variation in push force had a considerable influence on glove transmissibility, especially with forces less than the $50 \mathrm{~N}$ specified in ISO 10819 (1996). The reduced transmissibility obtained with 5 to 40-N forces might have arisen from: (i) the hand being less coupled with the vibrating handle with lower forces, reducing the contact area between the hand and the handle (Welcome et al. 2004), (ii) the change in pressure at the hand changing the viscoelastic properties of the gloves, or (iii) the change in force at the hand changing the mechanical impedance of the hand-arm system (Dong et al. 2005). The high dependence of glove transmissibility on the force indicates that the vibration isolation of some gloves will be improved by applying a force as light as the working conditions allow.

Glove transmissibility appears to be far more dependent on the push force than on the magnitude of vibration, irrespective of the type of glove (compare Figures 5 and 6). The variation in transmissibility with variation in force differed between the gloves, consistent with other studies (Gurram et al. 1994, Dong et al. 2002). Variations in the dynamic properties of glove materials with variations in force, suggest it is not sufficient to measure glove transmissibility with one combination of grip force and push force (30 N and $50 \mathrm{~N}$, respectively) as suggested in ISO 10819 (1996) (O'Boyle and Griffin 2004b). The forces measured at a handle are reported to reach $130 \mathrm{~N}$ (Kaulbars and Concettoni 2007), and an ISO standard for tool tests (e.g. chipping hammers, rock drills, pavement breakers and jackhammers) suggests the maximum feed/push force may reach $200 \mathrm{~N}$ (Dong et al. 2005). It is easy to conclude that gloves for specific working conditions should be assessed with an appropriate range of applied forces, and not a single intermediate force. 
The results of this study show high inter-subject variability in glove transmissibility, consistent with previous studies (e.g. Griffin 1998, Hewitt 1998, Boileau et al. 2002). The coefficients of variation in the overall transmissibilities across subjects (0.049 to 0.206 over all conditions) were generally greater than the coefficients of variation across the gloves $(0.039$ to 0.092 over all conditions). The condition with $2.0 \mathrm{~ms}^{-2}$ vibration magnitude and $50 \mathrm{~N}$ push force was included in both parts of the study and gave broadly similar TR and CoV values in the two sessions (Table 1). A comparison of Figures 4 and 7 shows that inter-subject variability can have a greater influence on the vibration reduction performance of a glove than the characteristics of the glove. It follows that if a glove is tested with only three subjects (as required by ISO 10819:1996) it could pass or fail by an appropriate or inappropriate selection of the subjects.

The variability within subjects may be attributable to the dynamic responses of different hands, which may depend on hand size and posture and the contact area with the handle, although in this study no correlation was found between hand circumference and glove transmissibility. There is currently insufficient information to specify how the hand characteristics should be controlled so that tests conducted with small numbers of subjects in different laboratories are comparable.

The factors investigated here are not the only factors that need to be understood before the test of the effectiveness of gloves in attenuating tool vibration can be optimised. The assumed sensitivity of the hand to vibration and the assumed spectra for the vibration on tools are of great importance (Griffin, 1998). A change to the frequency weighting for evaluating hand-transmitted vibration could make dramatic changes to whether a glove will be deemed to be beneficial. The spectra $M$ and $H$ assumed in ISO 10819:1996 are unrepresentative of the vibration on many tools: it is possible for a glove to provide apparently useful attenuation with spectrum $\mathrm{M}$ and $\mathrm{H}$ but not provide useful attenuation of the vibration on a tool, and vice versa. The gripping force was not studied here but remains important since it greatly complicates the conduct of tests made according to ISO 10819:1996. The complication of controlling gripping force will need to be justified if it is to be retained in a future standard. Consistent with the current standard, the present study investigated factors influencing the transmission of vibration to the palm of the hand, but it may be argued that vibration of the fingers is of greater importance. The vibration of the fingers, which may better indicate the risks of vibration-induced white finger and some other aspects of the hand-arm vibration syndrome, will be influenced by the posture of the hand and the location of application of vibration to the hand (Concettoni and Griffin, 2009). Further research to improve understanding of how gloves influence the risks associated with hand- 
transmitted vibration, and how the influence of gloves on these risks can be assessed in a practical and reliable test, appears desirable.

\section{Conclusions}

The transmission of vibration through anti-vibration gloves to the palm of the hand depends on the force applied by the hand: increasing the force seems to increase the resonance frequency of the glove-hand system and increase glove transmissibility. A glove currently classified as an anti-vibration glove might not provide the expected vibration reduction when the force applied to the handle of a tool differs from the $50-\mathrm{N}$ force used when testing the glove according to ISO 10819 (1996). Variations in vibration magnitude have a relatively small effect on glove transmissibility. Inter-subject variability can have an effect on glove transmissibility that is greater than the influence of force, vibration magnitude, and differences between gloves.

\section{Acknowledgements}

We would like to thank Dr. Christopher H. Lewis for assisting with preparations for this study.

\section{References}

Aatola, S., 1989. Transmission of vibration to the wrist and comparison of frequency response function estimators. Journal of Sound and Vibration, 131(3), 497-507.

Besa, A.J., Valero, F.J., Suner J.L., Carballeria, J., 2007. Characterisation of the mechanical impedance of the human hand-arm system: The influence of vibration direction, handarm posture and muscle tension. International Journal of Industrial Ergonomics, 37, 225-231.

Boileau, P.É., Boutin, J., Rakheja, S., Dong, R.G., 2002. Critical evaluation of a laboratory test procedure for measuring the vibration transmissibility of gloves. 37th United Kingdom Conference on Human Responses to Vibration. Loughborough University, United Kingdom. 106-117.

Concettoni, E., Griffin, M.J., 2009. The apparent mass and mechanical impedance of the hand and the transmission of vibration to the fingers, hand, and arm. Journal of Sound and Vibration 325 (3), pp. 664-678.

Dong, R.G., McDowell, T.W., Welcome, D.E., Barkley, J., Warren, C., Washington, B., 2004. Effects of hand-tool coupling conditions on the isolation effectiveness of air bladder anti-vibration gloves. Journal of Low Frequency Noise, Vibration and Active Control, 23 (4), 231-248.

Dong, R.G., McDowell, T.W., Welcome, D.E., Rakheja, S., Caporali, S.A., Schopper, A.W., 2002. Effectiveness of a transfer function method for evaluating vibration isolation 
performance of gloves when used with chipping hammers. Journal of Low Frequency Noise, Vibration and Active Control, 21 (3), 141-156.

Dong, R.G., McDowell, T.W., Welcome, D.E., Warren, C., Wu, J.Z., Rakheja, S., 2009. Analysis of anti-vibration gloves mechanism and evaluation methods. Journal of Sound and Vibration, 321, 435-453.

Dong, R.G., Rakheja, S., McDowell, T.W., Welcome, D.E., Wu J.Z., Warren, C, Barkley, J., Washington, B., Schopper, A.W., 2005. A method for assessing the effectiveness of anti-vibration gloves using biodynamic responses of the hand-arm system. Journal of Sound and Vibration, 282, 1101-1118.

European Committee for Standardization, 1994. General requirements for gloves. EN-420.

Griffin, M.J., 1998. Evaluating the effectiveness of gloves in reducing the hazards of handtransmitted vibration. Occupational Environmental Medicine, 55, 340-348.

Griffin, M.J., Macfarlane, C.R. and Norman, C.D., 1982. The transmission of vibration to the hand and the influence of gloves. In: A.J. Brammer and W. Taylor, ed. Vibration Effects on the Hand and Arm in Industry. New York: John Wiley and Sons, 103-116.

Griffin, M.,J., 1990. Handbook of human vibration. London: Academic Press.

Gurram, R., Rakheja, S., Gouw, G.J., 1994. Vibration transmission characteristics of the human hand-arm and gloves. International Journal of Industrial Ergonomics, 13, 217234.

Gurram, R., Rakheja, S., Gouw, G.J., 1995. Mechanical impedance of the human hand-arm system subject to sinusoidal and stochastical excitations. International Journal of Industrial Ergonomics, 16, 135-145.

Hewitt, S., 1998. Assessing the performance of anti-vibration gloves - a possible alternative to ISO 10819. Annals of Occupational Hygiene, 42 (4), 245-252.

International Organization for Standardization 1996. Mechanical vibration and shock-handarm vibration-method for the measurement and evaluation of the vibration transmissibility of gloves at the palm of the hand. 10819:1996. Geneva, Switzerland: International Organization for Standardization.

International Organization for Standardization 2001. Mechanical Vibration. Measurement and evaluation of human exposure to hand-transmitted vibration. ISO 5349-1:2001. Geneva, Switzerland: International Organization for Standardization.

International Organization for Standardization 1998. Mechanical Vibration and Shock - HandArm Vibration - Method for Measuring the Vibration Transmissibility of Resilient Materials when Loaded by the Hand-Arm System. ISO-13753:1998. Geneva, Switzerland: International Organization for Standardization. 
Kaulbars, U., Concettioni, E., 2007. Industrial trials of a system for measurement of coupling forces. In: 11th International Conference on Hand-Arm Vibration. 3-7 June 2007 Bologna, Italy, 481-488.

Książek, M.A., Tarnowski, J., 2001. Influence of hand pushing on handle on displacements and accelerations of operator's hand measured by a non-contact method. In: 36th United Kingdom Group Conference on Human Response to Vibration, 12-14 September 2001 Farnborough, UK, 333-344.

O'Boyle, M.J., 2003. The effect of push force on vibration transmissibility to the hand of antivibration materials. In: 38th United Kingdom Conference on Human Responses to Vibration, 17-19 September 2003 Institute of Naval Medicine, Gosport, UK, 473-478.

O'Boyle, M.J., 2005. Effect of vibration magnitude on glove material transmissibility. In: 40th United Kingdom Conference on Human Responses to Vibration, 13-15 September 2005 Health and Safety Executive, Liverpool, UK, 7pp.

O'Boyle, M.J., Griffin, M.J. 2004a. Inter-subject variability in the measurement of the vibration transmissibility of gloves according to current standards. In: 9th International Conference on hand-arm vibration, 5-8 June 2001 Institut National de Recherche et de Securite, Nancy, France, 8pp.

O'Boyle, M.J., Griffin, M.J. 2004b. Transmissibility and dynamic stiffness of glove materials and the apparent mass of the hand. In: Reynolds, D. (ed.) Proceedings of the 10th International Conference on Hand-Arm Vibration, University of Nevada, Nevada, USA, , 417-427.

Paddan, G.S., 1996. Effect of grip force and arm posture on the transmission of vibration through gloves. In: 31st UK Informal Group Meeting on Human response to Vibration, 18-20 September 1996 Nuneaton, Warwickshire, UK.

Paddan, G.S., Griffin, M.J., 1997. Individual variability in the transmission of vibration through gloves. In: S.A. Robinson,ed. Contemporary Ergonomics. London: Taylor Francis, 320-325.

Paddan, G.S., 1997. Effect of pull force on the transmission of vibration trough the finger to the fingernail. In: 32th United Kingdom Group Meeting on Human Response to Vibration, 17-19 September 1997 University of Southampton, UK, 459-469.

Paddan, G.S., 2001. Effect of measurement period on the testing of antivibration gloves. In: 36th United Kingdom Group Conference on Human Responses to Vibration, 12-14 September 2001 Centre for Human Sciences, Qinetiq, Farnborough, UK, 345-357.

Paddan, G.S., 2002. A possible incorrect use of a standard for testing of antivibration gloves. In: United Kingdom Conference on Human Responses to Vibration, 18-20 September 2002 Department of Human Sciences, Loughborough University, UK, 142-156. 
Pyykkö, I., Färkkila, M., Toivanen, J., Korhonen, O., Hyvärinen, J., 1976. Transmission of vibration in the hand-arm system with special reference to changes in compression force and acceleration. Scandinavian Journal of Work Environment \& Health, 2, 87-95.

Rakheja, S., Dong, R., Welcome, D., Schopper, A.W., 2002. Estimation of tool specific isolation performance of anti-vibration gloves. International Journal of Industrial Ergonomics, 30, 71-87.

Reynolds, D.D., Keith, R.H., 1977. Hand-arm vibration, part I: analytical model of the vibration response characteristics of the hand. Journal of Sound and Vibration, 51(2), 237-253.

Smutz, W.P., Dong, R.G., Han, B., Schopper, A.W., Welcome, D.E., Warren, C., Kashon, M.L., 2002. A method for reducing adaptor misalignment when testing gloves using ISO 10819. Annals of Occupational Hygiene, 46 (3), 309-315.

Welcome, D., Rakheja, S., Dong, R., Wu, J.Z., Schopper, A.W., 2004. An investigation on the relationship between grip, push and contact forces applied to a tool handle. International Journal of Industrial Ergonomics, 34, 507-518. 
Table 1. Mean, minimum, and maximum $T R$ values for each condition and the corresponding coefficients of variation (CoV). Data from 12 subjects.

\begin{tabular}{|c|c|c|c|c|c|c|c|c|c|c|c|c|c|c|c|}
\hline \multirow{2}{*}{$\begin{array}{l}\text { Magnitude } \\
\mathrm{ms}^{-2} \text { r.m.s. }\end{array}$} & \multirow{2}{*}{$\begin{array}{c}\text { Push } \\
\text { force } \\
\mathbf{N}\end{array}$} & \multicolumn{3}{|c|}{ Glove 1} & \multicolumn{3}{|c|}{ Glove 2} & \multicolumn{3}{|c|}{ Glove 3} & \multicolumn{3}{|c|}{ Glove 4} & \multicolumn{2}{|c|}{ all gloves } \\
\hline & & $T R$ & $\begin{array}{l}\text { Min } \\
\text { Max }\end{array}$ & CoV & $T R$ & $\begin{array}{l}\text { Min } \\
\text { Max }\end{array}$ & CoV & $T R$ & $\begin{array}{l}\text { Min } \\
\text { Max }\end{array}$ & CoV & $T R$ & $\begin{array}{l}\text { Min } \\
\text { Max }\end{array}$ & CoV & $T R$ & CoV \\
\hline 0.25 & \multirow{6}{*}{50} & 0.77 & $\begin{array}{l}0.63 \\
0.88\end{array}$ & 0.106 & 0.91 & $\begin{array}{l}0.81 \\
0.98\end{array}$ & 0.049 & 0.82 & $\begin{array}{l}0.72 \\
0.95\end{array}$ & 0.094 & 0.93 & $\begin{array}{l}0.79 \\
1.04\end{array}$ & 0.097 & 0.86 & 0.089 \\
\hline 0.5 & & 0.76 & $\begin{array}{l}0.65 \\
0.86\end{array}$ & 0.096 & 0.92 & $\begin{array}{l}0.82 \\
0.10\end{array}$ & 0.062 & 0.80 & $\begin{array}{l}0.69 \\
0.90\end{array}$ & 0.095 & 0.91 & $\begin{array}{l}0.59 \\
1.02\end{array}$ & 0.138 & 0.85 & 0.089 \\
\hline 1.0 & & 0.76 & $\begin{array}{l}0.60 \\
0.88\end{array}$ & 0.111 & 0.91 & $\begin{array}{l}0.80 \\
1.01\end{array}$ & 0.079 & 0.82 & $\begin{array}{l}0.69 \\
0.97\end{array}$ & 0.106 & 0.87 & $\begin{array}{l}0.57 \\
1.01\end{array}$ & 0.142 & 0.84 & 0.076 \\
\hline 2.0 & & 0.79 & $\begin{array}{l}0.65 \\
0.92\end{array}$ & 0.105 & 0.91 & $\begin{array}{l}0.79 \\
1.01\end{array}$ & 0.085 & 0.79 & $\begin{array}{l}0.56 \\
0.98\end{array}$ & 0.151 & 0.84 & $\begin{array}{l}0.55 \\
1.00\end{array}$ & 0.157 & 0.83 & 0.069 \\
\hline 4.0 & & 0.79 & $\begin{array}{l}0.66 \\
0.90\end{array}$ & 0.101 & 0.90 & $\begin{array}{l}0.72 \\
0.10\end{array}$ & 0.094 & 0.80 & $\begin{array}{l}0.61 \\
0.97\end{array}$ & 0.143 & 0.83 & $\begin{array}{l}0.56 \\
0.10\end{array}$ & 0.163 & 0.83 & 0.061 \\
\hline 8.0 & & 0.80 & $\begin{array}{l}0.68 \\
0.92\end{array}$ & 0.102 & 0.88 & $\begin{array}{l}0.75 \\
0.98\end{array}$ & 0.098 & 0.81 & $\begin{array}{l}0.58 \\
0.98\end{array}$ & 0.138 & 0.81 & $\begin{array}{l}0.51 \\
0.99\end{array}$ & 0.176 & 0.82 & 0.046 \\
\hline \multirow{6}{*}{2.0} & 5 & 0.51 & $\begin{array}{l}0.40 \\
0.65\end{array}$ & 0.146 & 0.62 & $\begin{array}{l}0.46 \\
0.83\end{array}$ & 0.206 & 0.61 & $\begin{array}{l}0.43 \\
0.86\end{array}$ & 0.190 & 0.55 & $\begin{array}{l}0.40 \\
0.71\end{array}$ & 0.108 & 0.57 & 0.087 \\
\hline & 10 & 0.60 & $\begin{array}{l}0.44 \\
0.81\end{array}$ & 0.201 & 0.74 & $\begin{array}{l}0.42 \\
0.93\end{array}$ & 0.196 & 0.67 & $\begin{array}{l}0.50 \\
0.87\end{array}$ & 0.162 & 0.71 & $\begin{array}{l}0.50 \\
0.82\end{array}$ & 0.151 & 0.68 & 0.092 \\
\hline & 20 & 0.67 & $\begin{array}{l}0.50 \\
0.89 \\
\end{array}$ & 0.170 & 0.82 & $\begin{array}{l}0.52 \\
0.96\end{array}$ & 0.160 & 0.74 & $\begin{array}{l}0.56 \\
0.94\end{array}$ & 0.157 & 0.78 & $\begin{array}{l}0.57 \\
0.88\end{array}$ & 0.119 & 0.75 & 0.085 \\
\hline & 40 & 0.73 & $\begin{array}{l}0.62 \\
0.93\end{array}$ & 0.123 & 0.86 & $\begin{array}{l}0.61 \\
1.02\end{array}$ & 0.172 & 0.80 & $\begin{array}{l}0.64 \\
0.98\end{array}$ & 0.135 & 0.81 & $\begin{array}{l}0.68 \\
0.93\end{array}$ & 0.080 & 0.80 & 0.066 \\
\hline & 50 & 0.78 & $\begin{array}{l}0.69 \\
0.89\end{array}$ & 0.088 & 0.88 & $\begin{array}{l}0.70 \\
1.05\end{array}$ & 0.145 & 0.81 & $\begin{array}{l}0.62 \\
0.96\end{array}$ & 0.126 & 0.83 & $\begin{array}{l}0.65 \\
0.95\end{array}$ & 0.113 & 0.82 & 0.053 \\
\hline & 80 & 0.79 & $\begin{array}{l}0.63 \\
0.93\end{array}$ & 0.100 & 0.87 & $\begin{array}{l}0.68 \\
0.99\end{array}$ & 0.136 & 0.82 & $\begin{array}{l}0.62 \\
0.97\end{array}$ & 0.125 & 0.84 & $\begin{array}{l}0.64 \\
0.97\end{array}$ & 0.109 & 0.83 & 0.039 \\
\hline
\end{tabular}


Table 2. Statistical significance (i.e. $p$-values) for the influence of vibration magnitude on glove transmissibility at preferred octave centre frequencies $\left({ }^{*} p \leq 0.05\right.$; ${ }^{* *}$ $p \leq 0.005$; Friedman test).

\begin{tabular}{|c|c|c|c|c|}
\hline $\begin{array}{c}\text { Frequency } \\
(\mathbf{H z})\end{array}$ & \multicolumn{4}{|c|}{$p$ values } \\
\cline { 2 - 5 } & Glove 1 & Glove 2 & Glove 3 & Glove 4 \\
\hline 16 & 0.239 & $0.034^{*}$ & 0.054 & $0.004^{* *}$ \\
\hline 31,5 & $0.019^{*}$ & $0.002^{* *}$ & 0.077 & 0.866 \\
\hline 63 & 0.081 & $0.018^{*}$ & $0.000^{* *}$ & $0.001^{* *}$ \\
\hline 125 & 0.567 & $0.014^{*}$ & 0.259 & $0.010^{*}$ \\
\hline 250 & 0.630 & $0.045^{*}$ & 0.159 & 0.063 \\
\hline 500 & 0.153 & 0.745 & 0.281 & $0.007^{*}$ \\
\hline 1000 & 0.879 & $0.005^{* *}$ & 0.312 & $0.001^{* *}$ \\
\hline
\end{tabular}




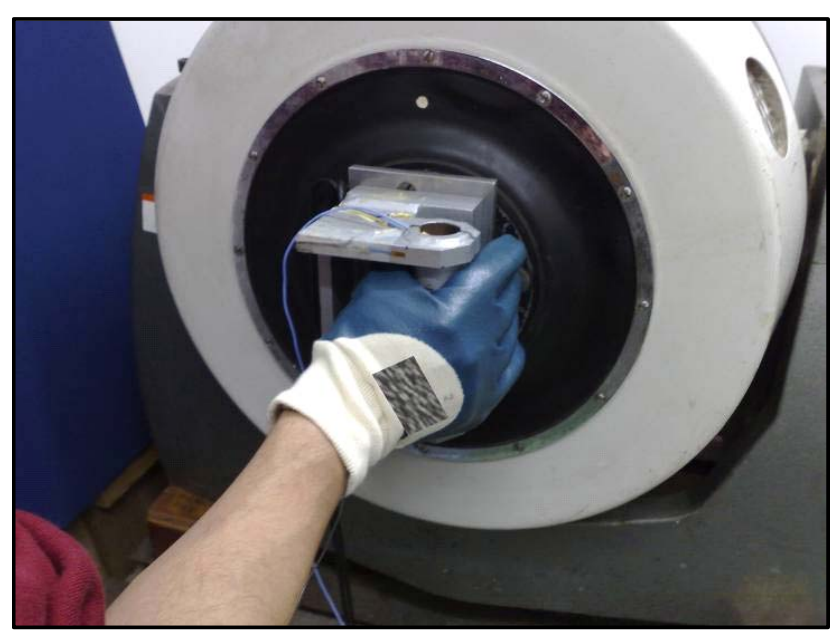

Figure 1. Pushing on the handle while applying no grip force when measuring glove transmissibility. 


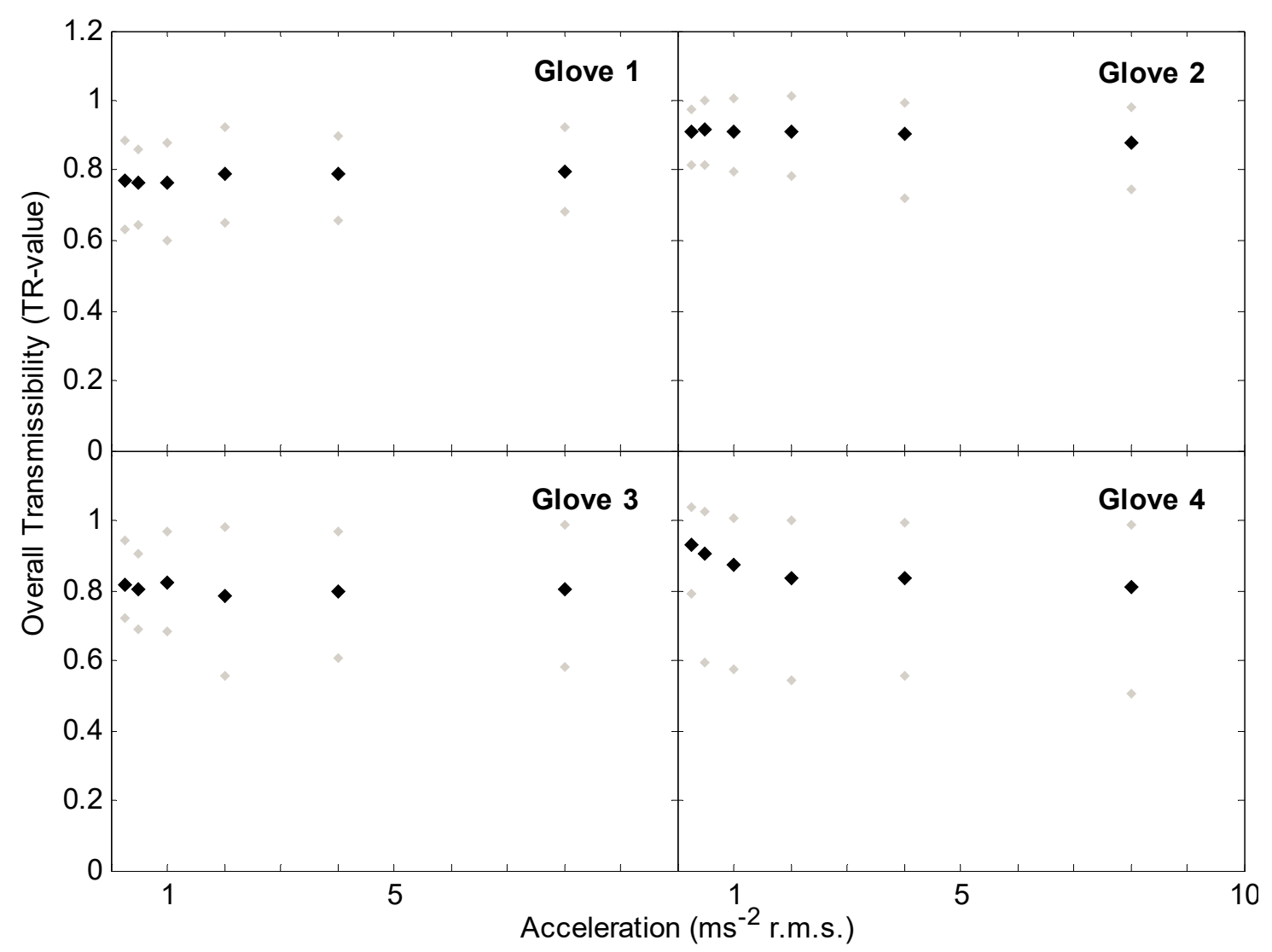

Figure 2. Overall transmissibilities (i.e. TR values) of four gloves obtained with a 50 $\mathrm{N}$ push force at vibration magnitudes from 0.25 to $8 \mathrm{~ms}^{-2}$ r.m.s. (mean, minimum and maximum values for 12 subjects). 


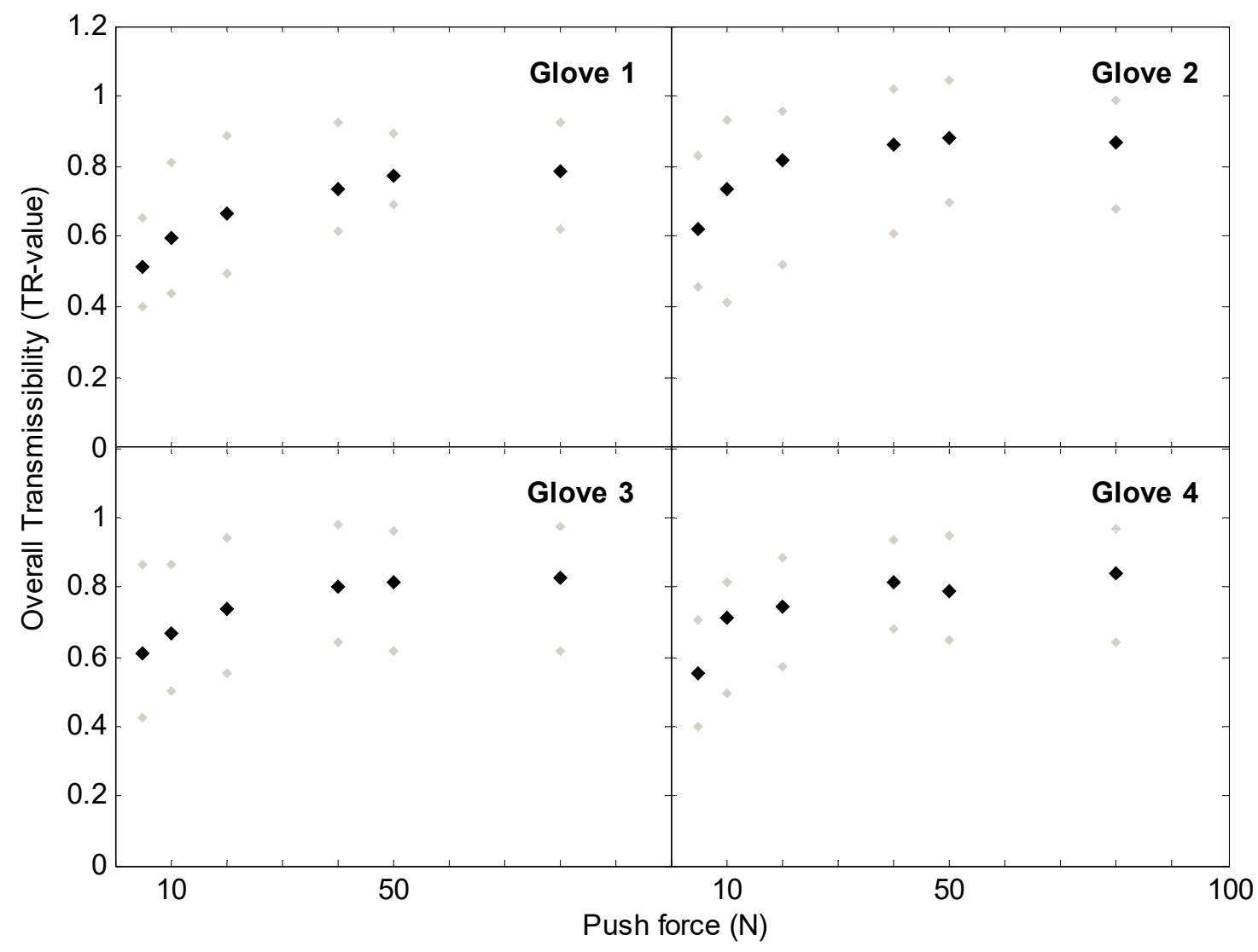

Figure 3. Overall transmissibilities (i.e. TR values) of four gloves obtained with 2.0 $\mathrm{ms}^{-2}$ r.m.s. vibration and handle push forces from 5 to $80 \mathrm{~N}$ (mean, minimum and maximum values for 12 subjects). 


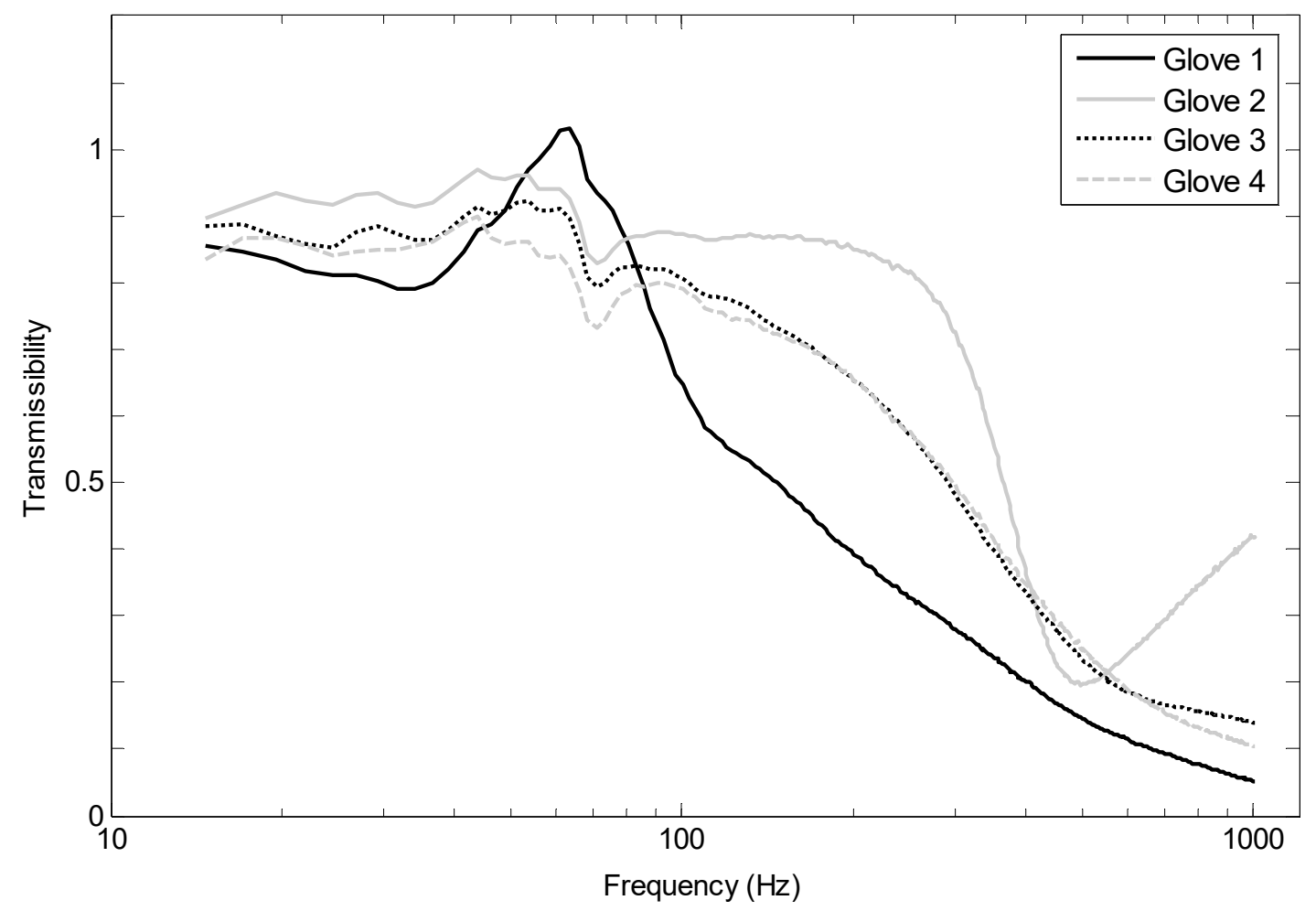

Figure 4. Transmissibility as a function of frequency for four gloves obtained with 2.0 $\mathrm{ms}^{-2}$ r.m.s. and a $50-\mathrm{N}$ push force (means of 12 subjects). 


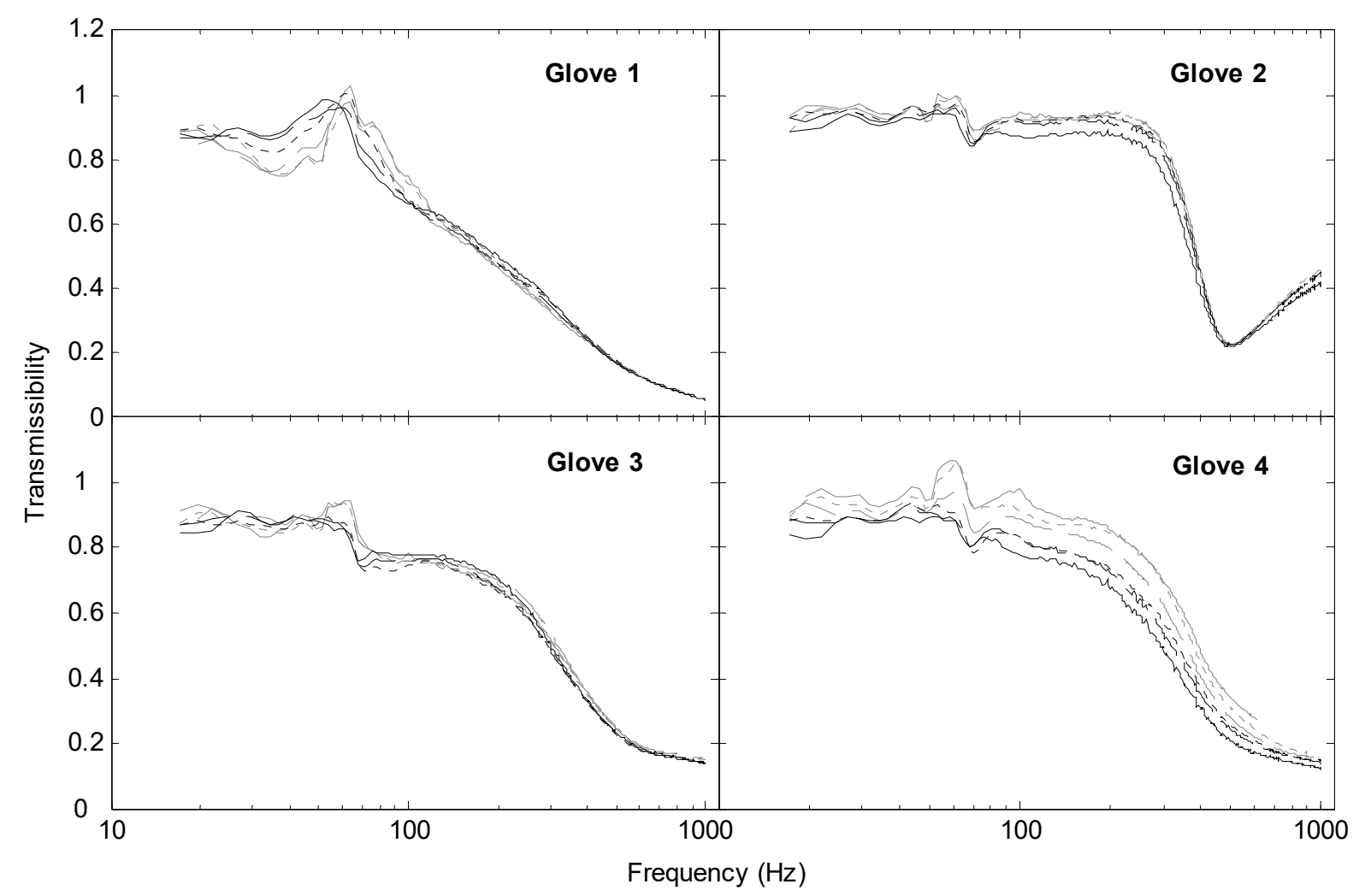

Figure 5. Effect of vibration magnitude on the transmissibility of four gloves as a function of frequency with $50-\mathrm{N}$ handle push force (means for 12 subjects: $-0.25 \mathrm{~ms}^{-2}$ r.m.s.; .... $0.5 \mathrm{~ms}^{-2}$ r.m.s.; ---- $1 \mathrm{~ms}^{-2}$ r.m.s. ${ }^{2} ; \ldots .2 \mathrm{~ms}^{-2}$ r.m.s.; ---- $4 \mathrm{~ms}^{-2}$ r.m.s.; $-8 \mathrm{~ms}^{-2}$ r.m.s.; frequency-weighted using $W_{\mathrm{h}}$ according to ISO 5349.1:2001)). 


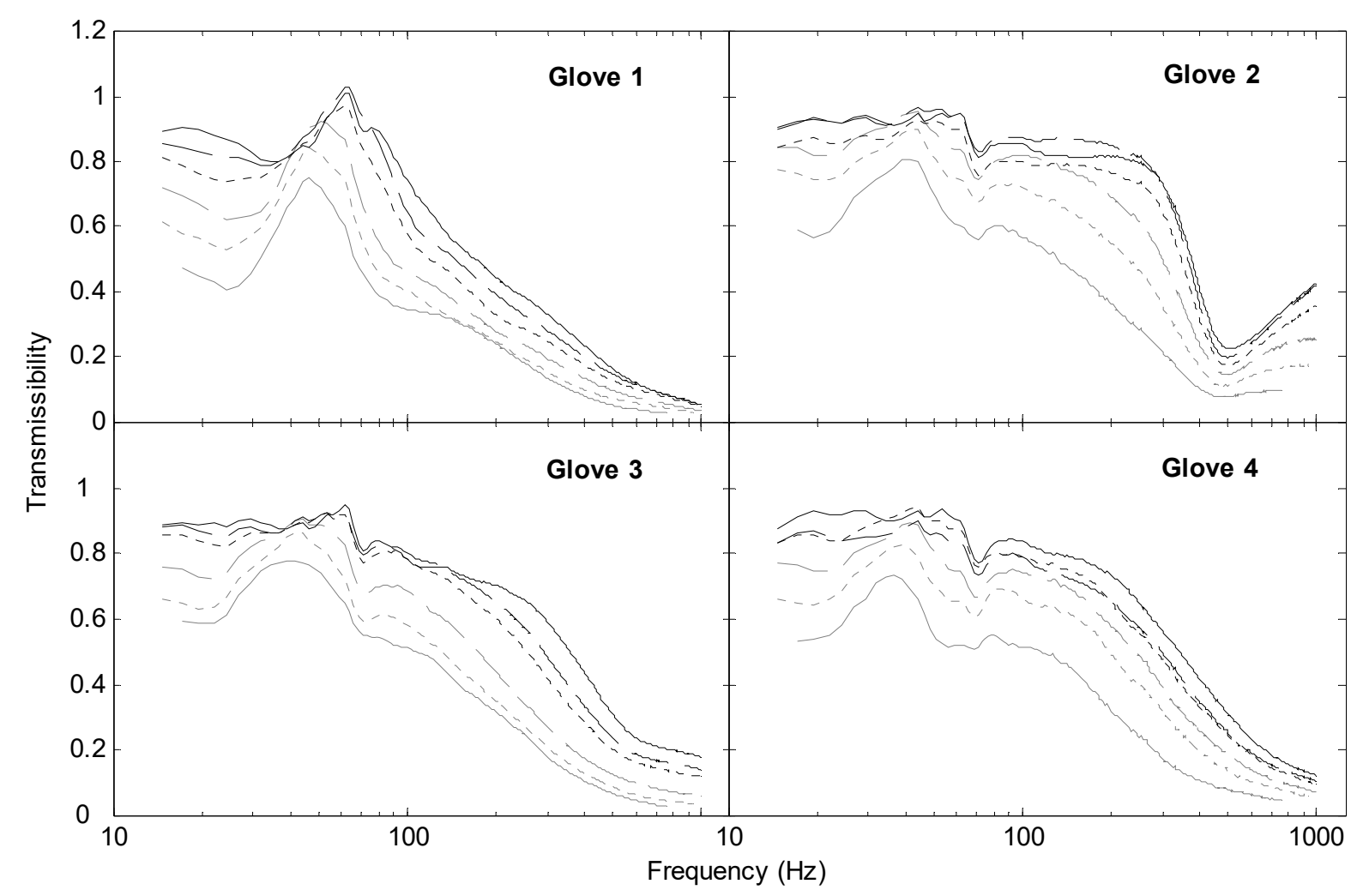

Figure 6. Effect of push force on the transmissibility of four gloves as a function of frequency with $2.0 \mathrm{~ms}^{-2}$ r.m.s. vibration (means for 12 subjects: $-5 \mathrm{~N} ; \ldots$. $10 \mathrm{~N} ;---20 \mathrm{~N} ; \ldots .40 \mathrm{~N} ;----50 \mathrm{~N} ;-80 \mathrm{~N})$. 


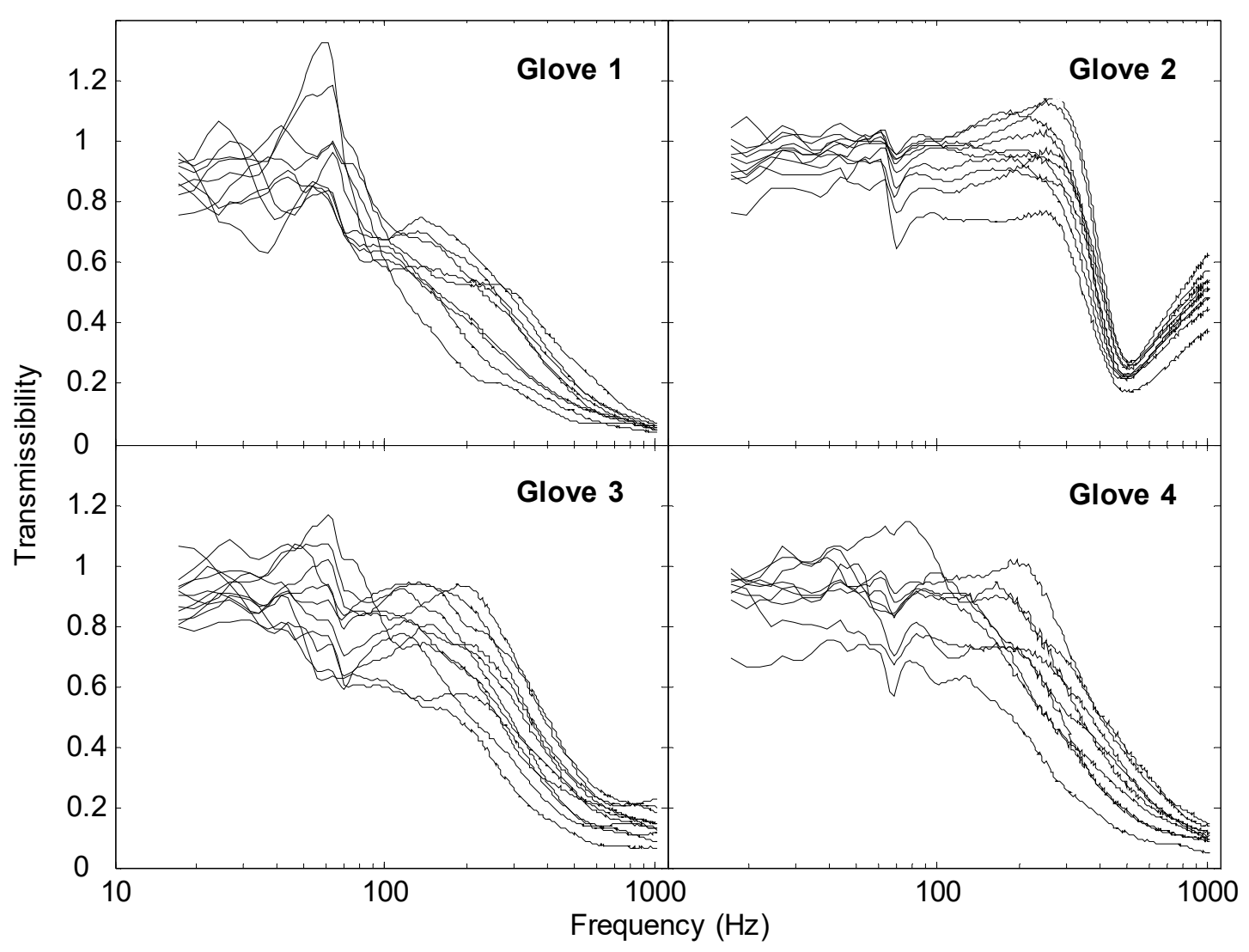

Figure 7. Individual variability in the transmissibility of four gloves as a function of frequency with a $50-\mathrm{N}$ handle push force and $4.0 \mathrm{~ms}^{-2}$ r.m.s. vibration (frequency-weighted using $W_{\mathrm{h}}$ according to ISO 5349.1:2001). 